\title{
ESCOLIOS A LA LEY 30/81 DE 7 DE JULIO
}

Luis Fernando SAURA MARTINEZ

Profesor de Derecho Civil 



\section{I.-DE LA RATIFICACION POR PODER DE LA DEMENDA POR MUTUO ACUERDO.}

Dentro de las dudas planteadas por las normas procesales de la Ley $30 / 81$ de 7 de julio al inicio de la vigencia, se inscribía la referente a ser o no precisa la comparecencia personal de los conyuges, a fin de ratificar la demanda de separación o de divorcio interpuesta por ellos de común acuerdo.

Ciertamente, en aquellos primeros momentos eran perfectamente sostenibles las dos posturas al respecto, dado el tenor del número 4 de la Disposición Adicional 6. ${ }^{\text {, }}$ y la ausencia de jurisprudencia acerca del mismo.

Dice, en efecto, el referido número 4: «En el plazo de tres días a contar desde la presentación de la petición, el Juez requerirá a las partes para que dentro de igual plazo se ratifiquen por separado en su petición de separación o divorcion.

Manteniendo la postura favorable a la necesaria comparecencia personal de los cónyuges a efectos de ratificación, entendía Vega Sala: «Esta ratificación, dice la ley, deberán hacerla los esposos por separado, y entendemos que personalmente y no por poder, pues la finalidad parece que entendemos que personalmente y no por poder, pues la finalidad parece que es la comprobación de la libertad con que acuden al divorcio, y aceptan los pactos del convenio, de lo contrario no tendría sentido alguno que tuvieran que hacerlo por separadow(1).

En el mismo sentido, Entrena Klett apuntaba: "La manifestación acorde de ambos consortes de querer separarse o divorciarse tiene que hacerse a la presencia judicial y por separadow(2).

La postura contraria, mantenida por nosotros(3), se podía apoyar, fundamentalmente, en el hecho de la no exigencia expresa de dicho requisito por la ley, por lo que "ubi lex non distinguit nec nos distinguere debemus"; del propio modo, si al amparo del artículo 55 era posible contraer matrimonio mediante apoderado, no parecía dislate sostener la posibilidad de ratificación de la demanda de separación o divorcio también por el mismo medio; finalmente, importaba, asimismo, tener en consideración que las Dis- 
posiciones Adicionales de la ley $30 / 81$ son normas procesales a las que, subsidiariamente, han de ser de aplicación las establecidas por la Ley de Enjuiciamiento Civil que faculta, en diversos preceptos, la ratificación por medio de poder especial al caso.

En esta misma línea se pronuncia Fosar Benlloch, escribiendo: "No debe olvidarse para la interpretación de este precepto, que el Congreso, en su sesión de 22 de junio de 1981, rechazó expresamente en este punto la redacción dada a este párrafo por el Senado en la que se disponia que rel Juez requerirá a las partes para que en plazo de tres días a contar desde dicho acto se ratifiquen personalmente por separado en su petición de separación o divorcion. Por supuesto que por ser un acto trascendental no podrá ratificarse el Procurador si no tuviere poder especial al efecto. Las facultades generales características de un poder general para pleitos, no habilitan para dicha ratificaciónw(4).

Pero si el planteamiento doctrinal era razonable en sostenimiento de ambas posturas, habría de ser la interpretación judicial la que inclinara la balanza en uno u otro sentido, habiéndose pronunciado ya al respecto la Audiencia Territorial de Valencia, como pasamos a reseñar.

En el mes de septiembre de 1981, se planteo, ante un Juzgado de 1. ${ }^{2}$ Instancia de Elché, demanda de divorcio deducida por ambos cónyuges de común acuerdo, dándose la circunstancia de residir uno de ellos, por razones de trabajo, fuera de España. Prevista la ausençla de dicho cónyuge y a fin de soslayar el obstáculo de la ratificación de la demanda, se procedió a otorgar por éste poder general para pleitos, al que se añadió la siguiente frase: «Especiales para ratificar en nombre del poderdante la demanda de divorcio a interponer de común acuerdo con su esposa .D. ${ }^{a}$..... ante Juzgado de $1 .{ }^{\text {a }}$ Instancia de esta ciudad".

Oportunamente, recayó en el procedimiento de méritos providencia acordando la ratificación personal de los conyuges. Contra la referida providencia se interpuso recurso de reposicion, resuelto por Auto cuyo Considerando segundo decía: "Que independientemente de ello, es lo cierto que el párrafo cuarto de la disposición adicional sexta, de la ley antes citada, exige indefectiblemente y como requisito imprescindible para la admisión a trámite de la petición de divorcio suscrita por ambos conyuges; y de 
mutuo acuerdo, el de la ratificación ante el organo judicial y por separado de la citada petición, ello como garantía de que dichos conyuges han procedido con absoluta libertad al adoptar la decisión de interesar el divorcio, y de que en definitiva se hallan también de acuerdo con los hechos narrados en la demanda, en las causas de divorcio invocadas y en el convenio regulador de sus relaciones personales y patrimoniales, concediéndoles el citado precepto incluso la oportunidad de disentir a posteriori de un acuerdo al que se hubiera podido llegar antes. Se entiende, y así debe dejarse sentado, que es precisamente el trámite de la ratificación por separado y ante la judicial presencia, una de las piezas esenciales y claves en el procedimiento de divorcio por mutuo acuerdo, de forma que eludir tal trámite, supandría no sólo lesionar el principio de contradicción, esencial a todo proceso, que en el de mutuo acuerdo, y precisamente por ello, por partir de previo acuerdo se viene a concretar en la posibilidad de disentir a posteriori de una decisión anteriormente tomada".

Contra el Auto resolutorio del recurso de reposición se interpuso recurso de apelación ante la Audiencia Territorial de Valencia, cuya Sala Primera, se pronunció al respecto, mediante Auto de 17 de mayo de 1982, manifestando en su primer Considerando: «...que formulando por ambos cónyuges conjuntamente demanda de divorcio, interesando la disolución del matrimonio por este medio con aprobación del convenio regulador de efectos, se acuerda por el Juez la ratificación de los solicitantes por separado concediendo término para ello que pudiendo hacerlo la esposa presente, no es así por parte del marido ausente del territorio nacional por razón del trabajo, sin haber dejado poder especial a tal efecto, la actora insistiendo en la tesis sustentada en reposición de la referida providencia y ahora de su recurso contra el Auto que la desestimó, sostiene la valencia del poder general otorgado por el Sr.... a Procuradores con la cláusula genérica que inserta al folio 27 de los autos para algunos efectos de la referida demanda, y que lo aduce, en evitación de dilaciones; punto de vista éste, que no. puede aceptarse pues si el apartado $4 .^{\circ}$ de la Disposición Adicional $6 .^{a}$ de la Ley 30 de 7 de julio de 1981 ordena de manera imperativa que las partes se ratifiquen por separado en la petición de divorcio, es obvio que mientras tal exigencia no se cumpla no puede admitirse a trámite la demanda formulada en ese sentido; y no basta con la expresión que se lee al final del 
poder que-como se ha dicho-reviste matiz genérico pero no específico al fin de divorcio instado por la mujer y la aprobación del convenio regulador, y mientras no se aporte poder especial con esa finalidad concreta, o se produzca la ratificación en la forma dicha, se alza obstáculo insuperable para lo postulado inicialmente, porque además cabe como igualmente apunta el Juzgador, que la otra parte hubiese variado de postura en lo que se le atribuye presentado el escrito como presuntamente conforme, $y$ que no se puede lograr la convicción de ello si no hace dicho interesado una manifestación de voluntad concreta en tal sentido mediante la ratificación, o por otro medio específico fehaciente en derecho"s.

\section{DE LA.CAUSA 2. ${ }^{a} \cdot$ DEL ARTICULO 86 DEL CODIGO CIVIL}

Sin ser ninguna de las causas de divorcio recogidas en el artículo 86 del Código Civil modelo de perfección técnica, acaso sea la segunda de ellas la más imprecisa y ambigua, seguro chortal de las más extravagantes y peregrinas interpretaciones a la hora de su aplicación.

Por su virtud, pues, es causa de divorcio: "El cese efectivo de la convivencia conyugal durante al menos un año ininterrumpịdo desde la interposición de la demanda de separación personal, a petición del demandante o de quien hubiere formulado reconvención conforme a lo establecido en el artículo 82, una vez firme la resolución estimatoria de la demanda de separación o, si transcurrido el expresado plazo, no hubiera recaido resolución en la primera instancian.

Un intento de aproximación interpretativa a la causa de referencia, arroja, ineluctablemente, las inquietantes incongruencias siguientes:

1.-Si transcurrido un año ininterrumpido desde la interposición de la demanda de separación personal puede ejercitar la acción de divorcio tanto el conyuge actor como el que hubiera formulado reconvención, es evidente que se está premiando, tan arbitraria como inexplicablemente, al esposo cuya reconvención hubiere sido desestimada-muchas veces por ha- 
berla basado en ilusorias e inexistentes circunstancias, cuando no en desvergonzadas, injuriosas o indignantes acusaciones-.

2.-Si transcurrido un año desde la interposición de la demanda de separación personal no hubiese recaido sentencia, pero se hubiera dictado, pasado dicho plazo sentencia desestimatoria ¿se podrá interponer la demanda de divorcio en tanto que el transcurso de un año establecido por la causa que nos ocupa se ha producido efectivamente?.

Con relación al primer punto-posibilidad de interposición de la demanda de divorcio por el reconveniente vencido-la incongruencia se hubiera podido soslayar fácilmente, sustituyendo tan sólo dos palabras, de tal forma que, en lugar de disponer como lo hace «una vez firme la resolución estimatoria de la demanda de separación", hubiera establecido "una vez firme la resolución estimatoria de la demanda o reconvención". Teniendo en cuenta, por otra parte, que en su actual redacción, la palabra separación unida a la frase "resolución estimatoria de la demanda" es absolutamente superflua y reiterativa, en tanto la resolución sólo puede referirse, en este caso, al proceso separatorio.

Por lo que respecta a la segunda de tales incongruencias, es evidente que, dictada una sentencia desestimatoria de la separación, no podrá prosperar una demanda de divorcio presentada con posterioridad a aquélla y basada en haber transcurrido "de facto" el año sin haberse dictado sentencia en la primera instancia. No podrá prosperar en tanto pugna con el espíritu que el legislador, pensamos, quiso imprimir al respecto, a pesar de su desafortunada expresión.

Sobre este punto, se muestra dubitativo Fosar Benlloch, manifestando: "Lo que no puede asegurarse es que el demandante que se ha retrasado algunos días o meses después de vencer el plazo de un año desde la interposición de la demanda de separación y que se ve sorprendido por una sentencia adversa o desestimatoria de la demanda de separación pueda prevalerse de esta causa de divorcio, a partir de la sentencia adversa, lo que deja en la incertidumbre e inseguridad jurídica al que pretende hacer uso de esta causa de divorcio, obligándole a una-anormal-diligencia procesal; demandar sin demora el divorciom(5). 
Pero, todavía, conviene añadir a lo expuesto una nueva complicación, esta vez con ocasión del proceso consensual introducido por la Disposición Adicional 6. ${ }^{a}$ de la Ley $30 / 81, y$, más concretamente, en relación con su número $3 .^{\circ}$ que al referirse a los documentos a acompanar en cada caso por los conyuges litigantes, establece en su apartado $3 .^{\circ}$ : "En el supuesto del artículo 86,2. ${ }^{\circ}$ la resolución estimatoria de la demanda de separación o testimonio acreditativo de la interposición de la demanda de separación personal, siempre que el otro cónyuge se adhiera a la misma".

Frase, la última de este párrafo $3 .^{\circ}$, asaz perturbadora y de compleja matización, porque, ¿a qué demanda ha de adherirse? ¿a la de divorcio? ¿a la de separación?. La recta lectura del texto legal nos conduce a la de separación indudablemente, y ello, además, por cuanto se inscribe en el proceso consensuado que exige una actuación de consuno por los cónyuges, de suerte que, o habrán formulado ambos la demanda de divorcio, o lo habrá hecho uno de ellos con consentimiento del otro, - y es que es de suponer aparezca acreditado en la demanda por alguno de los medios válidos en derecho-a lo que se debe añadir la necesidad de su ratificación en todo caso, a tenor del número $4 .^{\circ}$ de la referida Adicional.

Sentado, pues, que la adhesión lo ha de ser a la demanda de separación, es interesante hacer algunas consideraciones a tal propósito, deslindando los dos supuestos posibles ínsitos en dicho párrafo $3 .^{\circ}, y$ asl, en el primero de ellos ¿qué explicación tiene la adhesión del otro cónyuge a la demanda cuando hubiera sido más lógico exigirla a la sentencia, cuando sea ésta la que se acompañe a la demanda de divorcio?. En la segunda hipótesis, cuando se aporte el testimonio de la interposición de la demanda de separación, ¿por qué adhesión cuando el cónyuge demandado podría haberse mantenido en rebeldía o, lo que es peor, contestado a la demanda, siquiera no hubiera reconvenido?.

Pero, en ambos casos; $1 .^{\circ}-i$ En qué momento y en qué proceso habrá de mostrarse la adhesión, en el de separación o en el de divorcio?. 2. ${ }^{\circ}$-El proceso de separación, necesariamente contencioso por esta vía, hubo de sustentarse en alguna de las causas del artículo 82 del Código, por lo que parece excesivo pedir al demandado, no ya que reconozca paladinamente, sino que se adhiera a una demanda en que, gran parte de las veces, figura- 
rá como adúltero, crápula, libertino, irresponsable, infractor de los deberes conyugales o paterno-filiales, etc. $3 .^{\circ}-¿$ Cómo se compadece este párrafo $3 .^{\circ}$ con el supuesto de haber prosperado la reconvención pero no la demanda de separación?.

A este respecto, apunta Etelvina Valladares: «...si todavía no se ha producido la resolución, es posible pasar de la separación a petición de uno de los cónyuges a la separación de mutuo acuerdo... Si todavía no ha recaido resolución judicial, habrá de adherirse el otro cónyuge a la demanda presentada por uno sólo de ellos como requisito previo a la solicitud de divorcio de mutuo acuerdos(6).

Habiendo oportunidad de proseguir el pleito por el cauce de la Adicional 6. ${ }^{a}$, en aplicación del apartado k) de la 5. ${ }^{a}$, el problema se puede solventar fácilmente. En caso de haberse ya dictado resolución en el proceso de separación, la exigencia estricta y literal de la disposición que comentamos hará, en la mayoría de los casos, absolutamente inviable la posibilidad de su ejercicio.

III

SENTENCIA DE DIVORCIO Y RECURSO DE AUDIENCIA EN REBELDIA

A diferencia del legislador de 1932 que, para la sustanciación de los procedimientos sobre divorcio, se decanto en favor del juicio declarativo en menor cuantía-con la oportuna adecuación a la materia a que habría de servir de cauce-, el legislador de 1981. ha preferido-siquiera nominalmente-el trámite señalado para los incidentes en los artículos 741 a 761 de la Ley de Enjuiciamiento Civil-con las modificaciones expresadas en la Ley 30/81 de 7 de julio-para encauzar, a su través, los litigios relativos a nulidades matrimoniales suscitados como consecuencia de las causas de nulidad previstas en los números 2 y 3 del artículo 73 del Código Civil, los referentes a separación y divorcio contenciosos, y a las demás que se formulen al amparo del Título IV del Libro I de dicho cuerpo legal y no tengan señalado un procedimiento específico. 
Esta referencia del legislador de 1981 impone, inexorable y previamente, la concreción conceptual del incidente. Valga al respecto, por su concisión y claridad, la definición que del mismo, y en su sentido forense, nos ofrece el Diccionario de la Real Academia: "Cuestión distinta del principal asunto del juicio, pero con él relacionada, que se ventila y decide por separado, a veces sin suspender el curso de aquél, y otras, suspendiéndolo, caso éste en que se denomina de previo y especial pronunciamiento".

$\mathrm{Y}$, precisamente, habrá de ser esta precisión conceptual la que nos obligue, seguidamente, a su análisis comparativo con la acepción que el proceso incidental adquiere en la Disposición Adicional 5. a de la Ley 30/81, y en este menester resalta, poderosamente, el cambio de naturaleza que la meritada ley imprime al procedimiento apuntado, de suerte tal que, desustanciándolo, lo vacía de su prístina significación para trocarlo, lisa y llanamente, en un proceso declarativo más, con todas las secuelas y derivaciones que tal categoría comporta, y que no pudo pasar desapercibida al legislador de 1981.

Líneas atrás, al referirnos a las preferencias del legislador de hogaño, añadíamos el adverbio "nominalmente", consectario no gratuito si compulsamos el procedimiento escogido por el legislador actual-incidental-con el que, en su día, eligiera el de 1932-el declarativo de menor cuantia-. El resultado del cotejo es tan sorprendente que, puesto a beber en las fuentes anteriores, ha «bebido" nuestro legislador hasta la referencia a no ser necesario el acto de conciliación previo. Referencia obligada al introducir un proceso de menor cuantía que, a tenor del artículo 460 de la Ley de Enjuiciamiento Civil, generalmente lo exige, pero superflua al referirlo a los incidentes, que nunca lo ha requerido en atención a su propia naturaleza; «incidunt in rem de que agitur».

A nuestro parecer, fue más acertada la adecuación del procedimiento de menor cuantía a las nuevas exigencias que comportaba la Ley de Divorcio y llamar a las cosas por su nombre, que recoger ese mismo procedimiento en su casi literalidad, pero trocándole el nombre y desvirtuando al tiempo la naturaleza del proceso cedente del apelativo.

Por otra parte, es oportuno destacar el párrafo que, bajo el epígrafe de Disposiciones Adjcionales, sirve de introducción a ellas, y que reza: "En 
tanto no se modifique la Ley de Enjuiciamiento Civil, se observarán las siguientes normas procesales".

La lectura del párrafo tranścrito, conduce a las conclusiones siguientes: $1{ }^{2}$-Paladina proclamación del carácter provisional de las referidas normas y, condignamente, de la manifiesta necesidad de modificar la mencionada ley procesal. $2 .^{a}$-Alusión expresa a esta ley que, consecuentemente, debe entenderse como supletoria en todo caso, y no solo en sus artículos 741 a 761.

La segunda de las anteriores conclusiones pone de relieve una situación posible, no prevista expresamente por la Ley 30/81, susceptible de producir consecuencias peeturbadoras de, en algunos casos, imposible reparación.

En efecto, la Disposición Adicional $3 .^{a}$ establece la competencia territorial para conocer de los procedimientos sobre nulidad, separación y di-

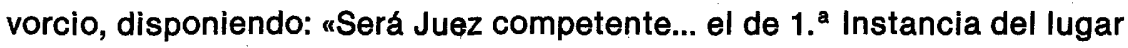
del domicilio conyugal. En el caso de residir los cónyuges en distintos partidos judiciales será Juez competente, a elección del demandante, el del último domicilio del matrimonio o el de residencia del demandado. Los que no tuviesen domicilio ni residencia fijos podrán ser demandados en el lugar en que se hallen o en el de su última residencia, a elección del demandante".

Ocurre, en ocasiones, que se puede ignorar el domicilio del demandado-y aún que se prefiere ignorar con evidente mala fe en este caso-previniendo para este supuesto el artículo 269 de la Ley de Enjuiciamiento Civil: "Cuando no conste el domicilio de la persona que deba ser notificada, o por haber mudado de habitación se ignore su paradero, se consignará por diligencia, y el Juez mandará que se haga la notificación fijando la cédula en el sitio público de costumbre, e insertándose en el Diario de Avisos donde lo hubiere, y si no en el Boletín Oficial de la Provincia...".

Situación nada infrecuente en los que a los procedimientos de separación y divorcio se refiere, a tenor de la multitud de Edictos publicados en la prensa cotidianá. 
Y como al amparo de nuestra Ley de Enjuiciamiento Civil se puede llegar hasta sentencia sin haberse citado ni emplazado personalmente al demandado ni una sola vez; sin haberle hecho en su persona siquiera una notificación, dispone para estos casos el artículo 777 de aquélla: "El demandado que por no tener domicilio conocido haya sido emplazado por edictos, será oído contra la sentencia firme cuando concurran todas las circunstancias siguientes: $1 .^{a}$ - Que la solicite dentro de un año contado desde la fecha de la publicación de la ejecutoria en el Boletín Oficial de la Provincia. 2. ${ }^{\mathrm{a}}$-Que acredite haber estado constantemente fuera del pueblo en que se ha seguido el juicio, desde que fue emplazado para él hasta la publicación de la sentencia. $3^{a}$-Que acredite asimismo que se hallaba ausente del pueblo de su última residencia al tiempo de publicarse en él los edictos para emplazarlon.

Y el artículo 778: «En todos estos casos, la pretensión que deduzca el litigante rebelde para que se le oiga contra la sentencia firme se sustanciará por los trámites establecidos para los incidentes, y con audiencia de los demás interesados que hayan sido parte en el pleito.

Como se trata de hipótesis reales y absolutamente posibles, causa extrañeza la falta de previsión del legislador sobre este punto, en tanto puede conducir a situaciones irreparables, al menos en aquellos supuestos en que habiendo recaido sentencia de divorcio, de conformidad con el artículo 89 del Código Civil, el cónyuge demandante hubiera contraido nuevo matrimonio en el interregno entre la publicación de la sentencia en el Boletín Oficial de la Provincia y su firmeza definitiva transcurrido un año desde la publicación de ésta.

Desde nuestro punto de vista el problema no tiene solución posible, en estricta y rigurosa aplicación de la legalidad vigente y, más concretamente, de la interpretación del artículo 89 del Código Civil en relación con el párrafo primero de la Disposición Adicional 9. ${ }^{2}$.

En los supuestos ordinario el problema se orilla mediante aplicación del artículo 787: "Las sentencias firmes dictadas en rebeldía del demandado podrán ser ejecutadas, salvo el derecho de éste para promover contra ellas el recurso de rescisión o audiencia expresado en los artículos anteriores. El que haya obtenido la sentencia no podrá, sin embargo, disponer 
libremente de las cosas de que se le haya dado posesión hasta haber transcurrido los términos antes señalados para oir al litigante condenado por ella...". Soluciones las de ambos párrafos que, es de presumir, no satisfarían ni al demandado rebelde, ni al nuevo consorte.

Sin embargo, el problema que nos ocupa podría hacer reverdecer la vieja polémica en torno de la diferencia entre inexistencia y nulidad matrimonial.

\section{NOTAS:}

(1) F. Vega Sala.-Sintesis práctica sobre la regulación del divorcio en España. Barcelona, 1981. p. 151. 589.

(2) Carlos María Entrena Klett.-Matrimonio, separación y divorcio. Pamplona, 1982. p.

(3) Luis Fernando Saura.- "En torno a las normas procesales de la Ley 30/1981 de 7 de julio. Dudas e incertidumbren. En Boletín llustre Colegio de Abogados de Madrid. Núm. 4/81. Octubre-Diciembre. pp. 29 y ss.

(4) Enrique Fosar Benlloch._Estudlos de Derecho de Familia. Tomo II. Vol. 2. ${ }^{\circ}$. Barcelona 1982. p. 728.

(5) E. Fosar Benlloch.-Op. cit. Tomo II, Vol. I. p. 237.

(6) Etelvina Valladares.-Nulidad, separacion y divorcio. Madrid 1982. p. 450. 